\title{
A Dinâmica Geoambiental das Dunas de Jericoacoara/CE entre os anos de 1958-2015
}

The Geoenvironmental dynamics of Jericoacoara dunes / CE between the years 1958-2014

\author{
PINHEIRO $^{1}$, M.V.A.
}

monivirna@yahoo.com.br

\begin{abstract}
Resumo
As dunas costeiras cumprem papel de destaque na dinâmica sedimentar atual ao contribuir para a distribuição equilibrada de sedimentos ao longo da costa, através do processo de transpasse costeiro. O objetivo desse artigo é apresentar as alterações morfológicas e ambientais na área de traspasse de Jericoacoara. A confirmação da redução das áreas dos campos de dunas, assim como seu aporte de sedimentos e a intensificação do uso e ocupação de ambientes costeiros para diversos fins gera um quadro ambiental preocupante e sinaliza a importância do planejamento ambiental e restrição de uso e ocupação mais intensa para as áreas de dunas móveis, com o risco de extinção desse patrimônio ambiental.
\end{abstract}

Palavras-chave: Transpasse, Litoral, Ceará.

\begin{abstract}
Coastal dunes meet prominent role in the current sediment dynamics to contribute to the balanced distribution of sediments along the coast, through the coastal transpassive process. The aim of this paper is to present the morphological and environmental changes in the crossover area of Jericoacoara. The confirmation of the reduction of the areas of dune fields, as well as its supply of sediment and the intensification of the use and occupation of coastal environments for different purposes generates a worrying environmental framework and indicates the importance of environmental planning and the use of restraint and more intense occupation for the areas of mobile dunes, with the risk of extinction of this environmental heritage.
\end{abstract}

Keywords: Bypass, Coast, Ceara.

\section{INTRODUÇÃO}

Os campos de dunas no Estado do Ceará são encontrados ao longo de toda sua extensão costeira em diferentes dimensões e morfologias. As dunas móveis migram sobre a planície, sendo interrompidas pelos estuários de rios e lagoas, seguindo a dinâmica eólica que se estabelece, predominantemente, no sentido SE-NW. São destaque as morfologias de lençóis de areia ou dunas compostas, barcanas e barcanóides. Já as dunas fixas, cobertas por vegetação arbórea-arbustiva e com formação de solos, margeiam o limite das dunas móveis com os tabuleiros costeiros, no interior do continente. Apresentam-se, geralmente, sem forma definida, porém também se encontram dunas do tipo Parabólicas, como as que ocorrem em Pecém e Iguape (PINHEIRO, 2015).

Por sua proximidade à linha do Equador, as médias climatológicas das temperaturas mensais no Ceará, especialmente na faixa litorânea, têm uma amplitude de variação anual relativamente pequena. As temperaturas máximas variam de $29,4^{\circ} \mathrm{C}$ (março) a $30,7^{\circ} \mathrm{C}$ (novembro). Os valores mínimos de $21,2{ }^{\circ} \mathrm{C}$ a $23,7^{\circ} \mathrm{C}$ são registrados em julho e no triênio (janeiro/ fevereiro e março) (FUNCEME, 2014). 
As condições pluviométricas no Estado mantêm uma estreita relação com o processo de deslocamento ou migração da Zona de Convergência Intertropical - ZCIT (AYOADE, 2003). No litoral, os índices pluviométricos são elevados, oscilando entre 1000 e 1350 mm anuais. É caracterizada por índices de precipitações do tipo tropical com estação de chuvas concentradas em 4 meses consecutivos, entre dezembro a maio, com um ciclo de variação anual. O regime eólico na costa cearense é marcado pela ação dos alísios que atingem a costa com direção predominante SE e $\mathrm{NE}$, e com menor frequência, de componente NE durante o primeiro semestre do ano. Considerando os dados do Aeroporto Pinto Martins em Fortaleza, a velocidade média mensal dos ventos para o período de 1993-2002 variou de 3 a 8,5 m/s (FUNCEME, 2014).

Esta situação eólica que ocorre em todo o litoral cearense é responsável pela migração das dunas sobre a planície costeira a velocidades estimadas situadas entre $6 \mathrm{~m} / \mathrm{ano}$ dentro dos lençóis de areia ou dunas compostas, e de cerca de $11 \mathrm{~m}$ /ano dentro dos campos de barcanas, levando em consideração a velocidade dos ventos no Ceará (MAIA, 1998).

A fisiografia litorânea do Estado do Ceará pode ser enquadrada, com algumas modificações, no modelo de "headland-bay-beach" de Yasso (1965). Segundo este autor, tal modelado é definido por uma faixa de praia posicionada a sotamar de um promontório, submetida a uma direção predominante de ataque de onda (CARVALHO et al., 2005).

Nesses setores de promontórios, em costas dominadas pela deposição de sedimentos ocorrem os chamados "headland bypass dune field" tratado a primeira vez por Tinley (1985). Na faixa continental, nessa ação os campos de dunas transpassam o promontório e chegam à enseada a sotamar, realimentando a faixa de praia, realizando o transpasse ou bypass costeiro. Já a nível marinho, os sedimentos transpassam o promontório e se depositam a sotamar da ponta, realizando o transpasse ou bypass litorâneo.

Em Jericoacoara, praia cearense localizada a $294 \mathrm{~km}$ de Fortaleza (Figura 01), a zona costeira tem como predominância a migração de dunas. Essa migração atua realizando o transpasse costeiro ao longo do promontório, sobretudo, por dunas do tipo barcanas. Na análise realizada a partir de fotografias aéreas do ano de 1958 as alterações de aporte de sedimentos e de morfologia se fazem presente, assim, nesse sentido, o objetivo do presente trabalho é analisar a dinâmica espaço-tempo dentro do campo de dunas de Jericoacoara entre os anos de 1958 e 2015.

\section{METODOLOGIA}

A perspectiva metodológica para a análise das áreas de dunas de transpasse costeiro do Ceará leva em consideração a complexidade da problemática do ambiente de dunas no Estado, que integra em seu bojo, aspectos naturais e sociais, fundamentais no entendimento da paisagem. 
O estudo tomou como referência a análise geoambiental, de inspiração geossistêmica, que conduz ao estudo das relações de interdependência existentes entre os componentes do meio natural e social. Os fundamentos metodológicos da análise geoambiental têm como diretriz principal a análise integrada da paisagem, de forma a permitir uma concepção globalizante e funcional do espaço, através do estudo das inter-relações entre os diversos elementos que a compõem, como indicado por Rodrigues e Silva (2002).

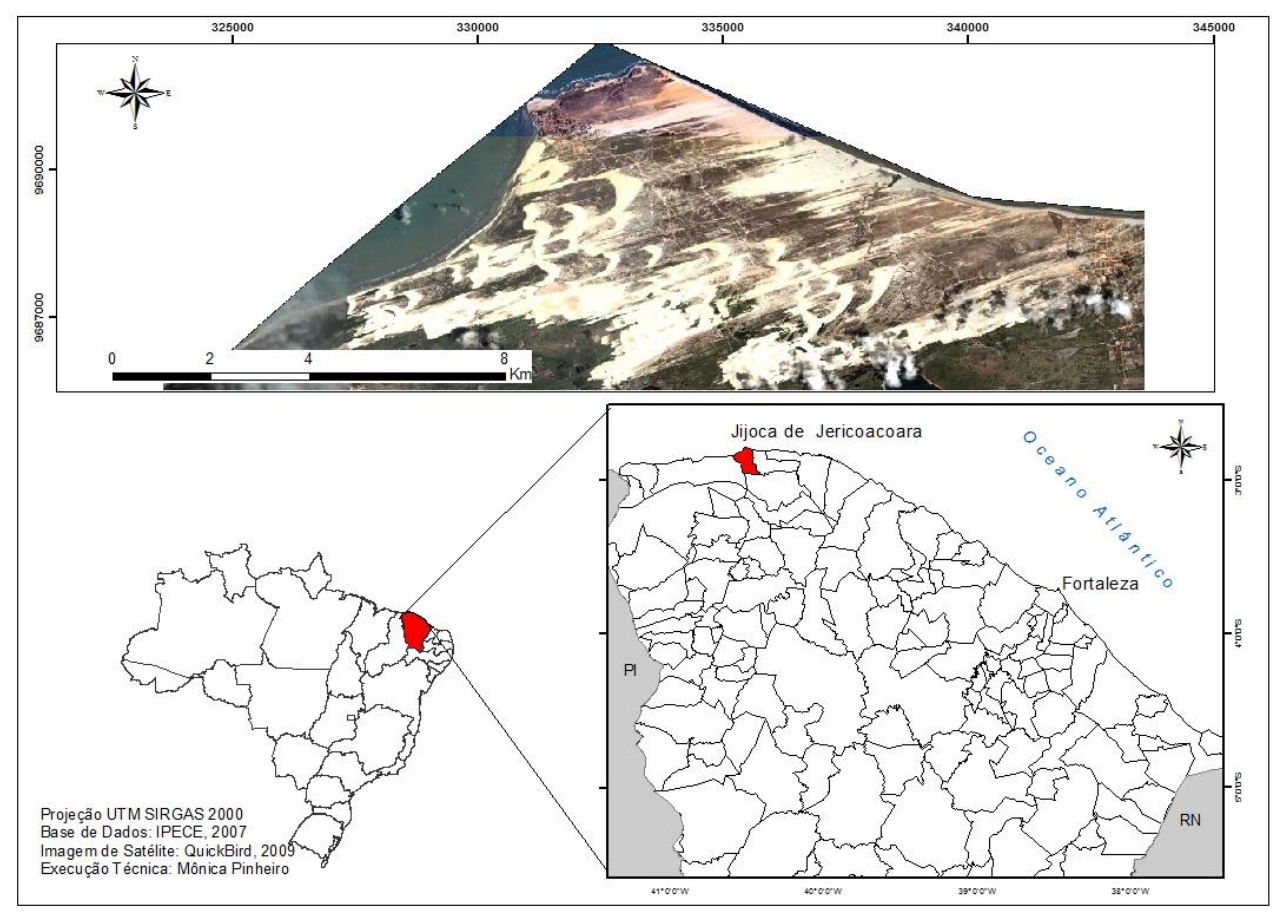

Figura 01. Localização da área de estudo. Fonte: Autor (2016).

Assim, foram realizados amplos levantamentos bibliográfico e cartográfico, seguidos da necessária triagem e análise, considerando a relação e relevância acerca do tema de estudo.

As imagens de satélite e fotografia aéreas foram georreferenciadas adotando-se o sistema de projeção UTM, zona 24S, datum SIRGAS 2000. Posteriormente, foi feito o processo de vetorização das imagens, a partir da interpretação visual, delimitando cada unidade geoambiental, através de criação de arquivos shapesfiles.

Para a confecção dos mapas do período anterior à urbanização foram utilizadas as fotografias aéreas do ano de 1958, disponibilizadas pelo Departamento Nacional de Obras Contra as Secas DNOCS. Essas fotografias representam o período de tempo disponível, com qualidade, de períodos anteriores à ocupação urbana ao longo da faixa costeira de Jericoacoara.

As fotografias aéreas foram digitalizadas, ou seja, transformado do formato analógico para o digital por meio de scanner. As fotografias encontram-se na escala de 1:25.000 e foram 
georreferenciadas e interpretadas para a vetorização das unidades geoambientais, através do software ArcGis 9.3. Para a composição dos mapas no período atual foram utilizadas as Imagens do Satélite QuickBird (2009).

A etapa de campo consistiu no reconhecimento e identificação das formas dunares de transpasse costeiro no promontório e seu ambiente, além da identificação de obstruções ao trânsito sedimentar ao longo do promontório. Também, determinou-se nessa etapa o estágio atual do processo de uso e ocupação e degradação associada na área do campo de dunas no setor analisado.

\section{RESULTADOS E DISCUSSÃO}

Em Jericoacoara as dunas migram sobre a planície de deflação em forma de cadeia de Barcanas e Barcanóides. Essa migração se estende por $10 \mathrm{~km}$ de largura entre a faixa de praia à barlamar do promontório e a enseada a sotamar. Parte das dunas adentram o continente até o limite com as dunas fixas. As dunas fixas não possuem forma definida, aplainando em direção aos Tabuleiros Costeiros (MEIRELES e SERRA, 2002).

Segundo Jimenez et al., (1999), o sistema de Jericoacoara é o único em que uma grande quantidade de areia contorna o promontório através da migração de dunas extremamente ativo, migrando em uma faixa média de $11 \mathrm{~m} / \mathrm{ano}$.

A ponta litorânea de Jericoacoara atua como uma barreira à deriva litorânea, acumulando grande quantidade de areias à barlamar. $\mathrm{O}$ volume de areias transportado pela deriva litorânea e acumulado na praia à barlamar, assim como a quantidade transportada pelo transpasse litorâneo, não são conhecidos (CLAUDINO-SALES e CARVALHO, 2014).

Segundo Meireles e Serra (2002), o promontório denominado de Ponta de Jericoacoara, formado de rochas pré-cambrianas quartzíticas e gnáissicas participou diretamente das oscilações do mar durante os dois eventos transgressivos definidos para esta região (máximos há aproximadamente 123.000 e 5.100 anos A.P.). Atuou como um tômbolo em condições de níveis mais elevados do que o atual, proporcionando uma dinâmica peculiar na construção da planície, diversificando a direção e sentido dos ventos, das ondas e a migração dos sedimentos ao longo da linha de praia (deriva litorânea) e para o interior do continente (deriva eólica).

No campo de dunas móveis as dunas barcanas apresentam as maiores altitudes, algumas com cerca de 50 metros. Em geral, a planície apresenta altitudes médias de 20 metros dentro do campo de dunas (PINHEIRO, 2015) como pode ser observado na figura 02.

Em tal contexto, ocorre acréscimo na faixa de praia por até $30 \mathrm{~km}$ a sotamar da ponta, dado o grande aporte de sedimentos fornecido pelas dunas de transpasse. Esse aporte permite também a construção de um grande esporão arenoso a sotamar do promontório, assim como provoca o 
soterramento do manguezal existente na desembocadura do rio Guriú, que se acha isolada pelo esporão, formando laguna (CLAUDINO-SALES e CARVALHO, 2014).

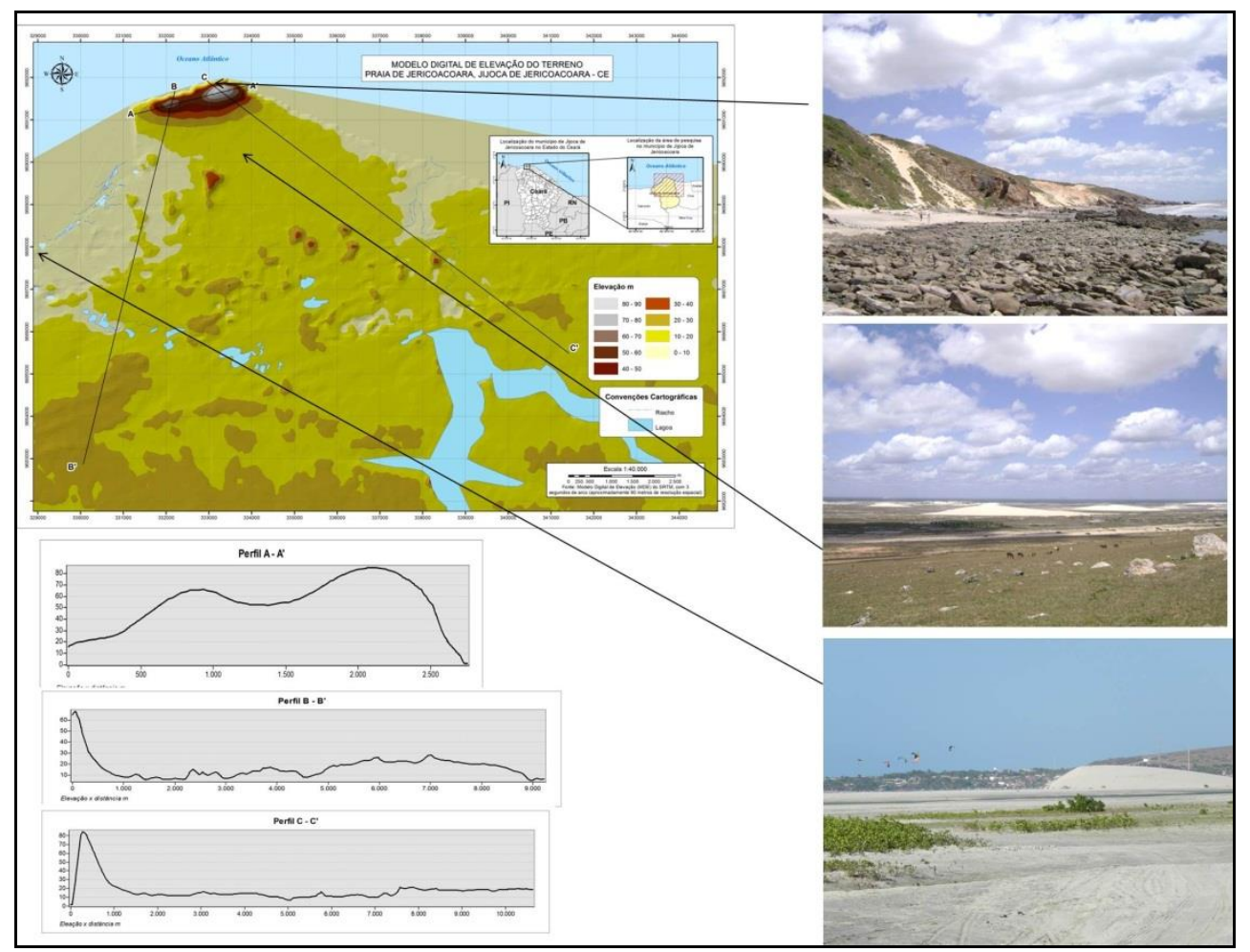

Figura 02. Modelo digital de elevação com perfis e fotos da área. Fonte: Autor (2015)

De acordo com o mapeamento realizado, no ano de 1958 as dunas móveis em Jericoacoara migravam sobre a planície recobrindo uma extensa área entre a faixa de praia e as dunas fixas e/ou lagoas com morfologias dunares pouco definidas (figura 03). Entre os anos de 1958 e 2015, houve uma redução da área de dunas móveis em Jericoacoara de 26,91\% ou 809,32 ha.

Contudo, a partir do mapeamento realizado, em Jericoacoara, o suprimento de sedimentos dentro do campo de dunas móveis foi claramente reduzido em função da diminuição do aporte de sedimentos que chegam à praia para a formação de dunas e não por interferências antrópicas na área.

Além disso, durante o período analisado mudanças morfológicas das dunas também foram identificadas. As dunas móveis se comportavam de modo geral como cadeia de barcanóides e em parte como Lençóis de Areia e atualmente migram, predominantemente, como barcanas isoladas. Essa transformação retrata uma evidência da redução de sedimentos para o campo de dunas, pois, de acordo com Tinley (1985), dunas barcanas são formadas quando há um menor suprimento de areias dentro do contexto costeiro. 


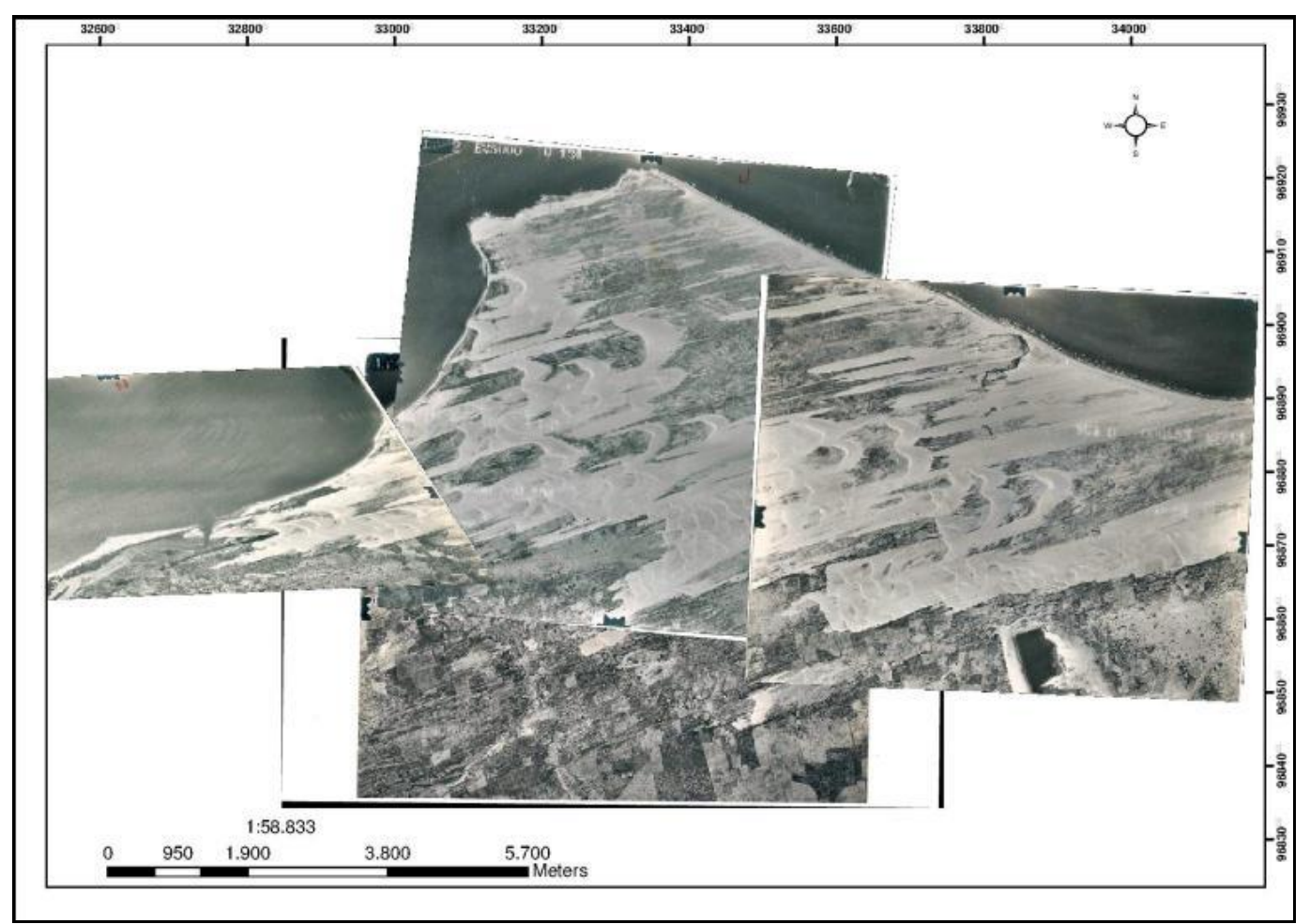

Figura 03. Planície costeira de Jericoacoara em 1958. Fonte: DNOCS

A figura 04 mostra a diminuição no aporte de sedimentos sobre a planície costeira com redução da área de dunas móveis e a migração em direção as dunas fixas e, principalmente a alteração morfológica sofrida entre os anos analisados, de dunas compostas a dunas barcanas.

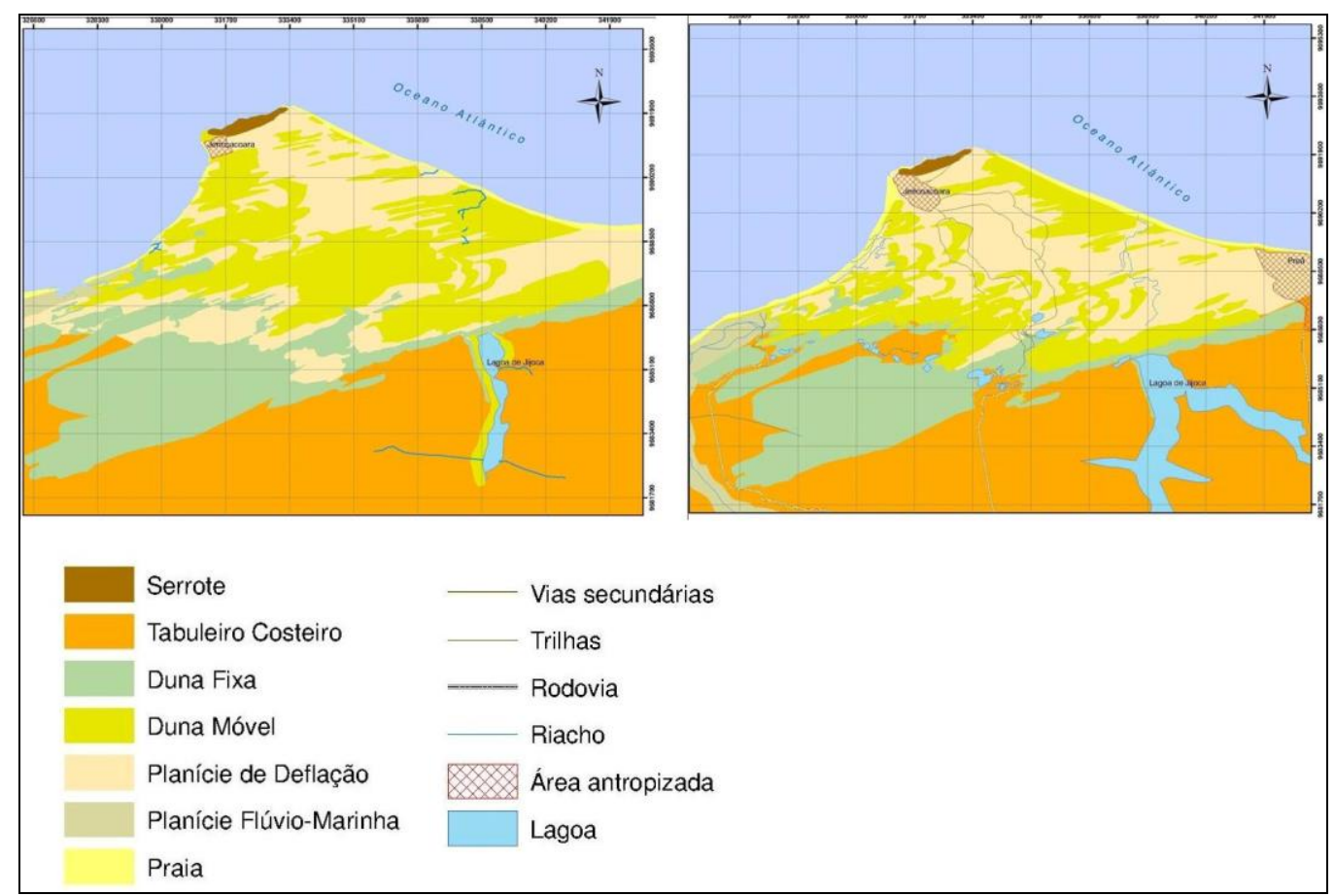

Figura 04. Alterações no campo de dunas de Jericoacoara. Em 1958 (esquerda) e 2015 (direita). Fonte: Autor (2015) 
A migração do campo de dunas móveis em direção às dunas fixas e à planície flúvio-marinha do Rio Guriú é evidente na análise espaço-temporal. Parte dessas dunas móveis foi fixada naturalmente contribuindo também na redução quantitativa desse campo de dunas. As dunas fixas apresentaram um pequeno aumento da sua área expandindo-se sobre as áreas de dunas e planície de deflação em cerca de $8 \%$.

A expansão da localidade de Jericoacoara em direção à planície de deflação também propiciou a redução de parte dos setores de transpasse costeiro. Esse crescimento passou de 27,10 ha em 1958 para 87,94 ha em 2014. A expansão da vila, muito em função da intensificação do turismo, vem ocupando cada vez mais espaços na planície de deflação como pode ser visto na figura 04.

O crescimento da malha urbana das localidades de Jericoacoara e Preá (localidade a leste de Jericoacoara) fica claro na planície. Além disso, a intensa movimentação de automóveis nas áreas de dunas e planície de deflação vem contribuindo para a alteração desses ambientes.

Apesar da proteção legal dada à praia de Jericoacoara a partir da criação da Unidade de Conservação (UC) do Parque Nacional de Jericoacoara, criada em 2002 e regulamentada em 2011, a área ainda sofre com suas limitações administrativas, principalmente ligadas à fiscalização de práticas, como por exemplo, o fluxo de veículos dentro da área do campo de dunas. Além disso, a crescente expansão urbana deve ser acompanhada e limitada dentro das condições ambientais e ecológicas de manutenção do equilíbrio costeiro.

As condições ambientais expostas a partir da análise realizada mostram que mesmo em área com maior preservação, com menores alterações antrópicas como em Jericoacoara, a dinâmica sedimentar apresenta-se comprometida em função das inúmeras intervenções ao longo da costa brasileira, o que vem ocasionando redução no aporte de sedimentos para praias e dunas. A continuidade desse processo pode levar à quebra no equilíbrio morfológico e ambiental de toda a faixa costeira.

\section{CONSIDERAÇÕES FINAIS}

Com o objetivo de entender e conhecer o campo de dunas de transpasse de Jericoacoara analisou-se o ambiente quanto aos seus aspectos evolutivos e morfodinâmicos, a partir do final da década de 1950 até os dias atuais. Com esse estudo, pode-se constatar relevante diminuição do aporte de sedimentos arenosos, afetando diretamente as paisagens dunares e consequentemente, redução de sedimentos na zona costeira do Ceará.

Verificou-se uma tendência geral de recuo nas áreas de dunas móveis com diminuição do aporte, surgimento de planícies de deflação e mudanças morfológicas no campo de dunas. A 
alteração identificada retrata a transformação de dunas barcanóides e lençóis de areia em dunas barcanas na planície de Jericoacoara.

Nesse sentido, o estudo mostra uma tendência regressiva das áreas de dunas, o que associada a atual subida geral do nível dos mares, pode trazer consequências negativas como a intensificação dos processos erosivos nas praias e a perda por completo das áreas de dunas móveis.

\section{REFERÊNCIAS}

AYOADE, J.O. Introdução à Climatologia para os Trópicos. Rio de Janeiro: Bertrand Brasil, 2003. 332p.

CARVAlHO, A. M.; DOMINGUES, J. M. L.; MAIA, L. P. A Influência da Estruturação do Embasamento Pré-Cambriano na Elaboração da Morfologia Costeira. Revista de Geologia, v. 18, n. 1, Fortaleza: 2005.

CLAUDINO-SALES, V.; CARVALHO, A. M. Dinâmica Costeira Controlada por Promontórios no Estado do Ceará, Nordeste do Brasil. Geociências, v. 33, n. 4, p.579-595, 2014.

FUNCEME. Fundação Cearense de Meteorologia. Precipitação. Dados Históricos, 2014.

JIMENEZ, J. A.; MAIA, L. P.; SERRA, J.; MORAIS, J. Aeolian dune migration along the Ceará coast, north-eastern Brazil. Sedimentology 46, 689-701, 1999.

MAIA, L. P. Procesos Costeros y Balance Sedimentario a lo Largo de Fortaleza (NE-Brasil): Implicaciones para una Gestion Adecuada de la Zona Litoral. Tesis Doctoral, Univ. Barcelona, 1998. 198p.

MEIRELES, A. J. A. e SERRA, J. R. Evolução paleogeográfica da planície costeira de Jericoacoara/Ceará. Mercator, v. 1, p. 79-94, Fortaleza: 2002.

PINHEIRO, M.V.A. Evolução Geoambiental das Dunas de Transpasse do Estado do Ceará. Tese de Doutorado apresentado ao programa de Pós Graduação em Ciências Marinhas Tropicais da Universidade Federal do Ceará, Fortaleza, 2015. 152p.

RODRIGUES, J.M.M e SILVA, E.V. A Classificação das Paisagens a partir de uma Visão Geossistêmica. Mercator, Ano 1, n 1 , Fortaleza: 2002.

TINLEY, K.L. Coastal Dune of South Africa. 1985.

\section{AGRADECIMENTOS}

Os resultados desse artigo derivam da tese de doutorado da autora, assim, agradecemos à Fundação Cearense de Apoio ao Desenvolvimento Científico e Tecnológico - FUNCAP pelo apoio 
concedido através da bolsa de estudo vinculada ao Programa de Pós-Graduação em Ciências Marinhas Tropicais da UFC.

Recebido em: 14/08/2016

Aceito para publicação em: 01/10/2016 